\title{
Structures and Optical Properties of Resins Containing Several Carboxylic Acids Neutralized with Barium Ion
}

\author{
Shuji Eguchi and Hideki Asano* \\ Hitachi Research Laboratory, Hitachi Ltd., 4026 Kuji-cho, \\ Ibaraki 319-12, Japan
}

(Received October 1, 1990)

\begin{abstract}
Monomer composites containing an aromatic carbozylic acid and methacrylic acid (or acrylic acid) partially neutralized with a barium compound showed good solubility in chlorostyrene at high barium ion concentrations, unlike composites containing only one carboxylic acid. The improved solubility was due to the presence of an ionic crosslink composed of the aromatic carboxylate ion and methacrylate (acrylate) ion bridged with a barium ion, which provided an effective structure for depressing the growth of ionic associations. The bulky structure also enabled resins to maintain their transparency after being copolymerized with chlorostyrene. The refractive indices and Abbe numbers of the resins were measured and differences in optical properties between various carboxylic acids were evaluated according to $\left(R_{\mathrm{u}}\right) / M_{\mathrm{u}}$ and the density in the Lorentz-Lorenz equation, where $\left(R_{\mathrm{u}}\right)$ and $M_{\mathrm{u}}$ are the unit molar refraction and residue molecular weight, respectively. The resins with acrylic acid had a higher refractive index without decrease of the Abbe number at the same barium content than those with methacrylic acid, due to the effect of the former on increased resin density. The introduction of an aromatic acid having a high molar refraction value led to increase of the refractive index, but its effect on the increase was small, because it caused a drop in resin density.

KEY WORDS Barium Salt / Carboxylic Acid / Transparent Resin

/ Refractive Index / Abbe Number / Molar

Refraction / Molar Volume /
\end{abstract}

Numerous studies on ion-containing polymers have been reported ${ }^{1-6}$ emphasizing their unique and interesting properties. The ionizations of copolymers of acrylic acid and methacrylic acid with ethylene, butadiene, and styrene result in a significant enhancement of optical clarities, tensile strengths, and melt viscosities. These polymers are known as "ionomers". Rare earth metal salts $\left(\mathrm{Dy}^{3+}, \mathrm{Er}^{3+}\right.$, $\mathrm{Eu}^{3+}$, and $\mathrm{Sm}^{3+}$ ) of copolymers of acrylic acid and methacryic acid with a vinyl monomer exhibit fluorescence under ultraviolet excitation. ${ }^{7}$

On the other hand, ionically crosslinked polymers can be obtained by copolymerization of polymerizable monomers containing an ionic bond with vinyl monomers. ${ }^{8}$ The physical properties of these polymers are also improved by introduction of metal salts. Recently, analogous with inorganic glasses, copolymers of polymerizable monomers containing heavy metal ions with vinyl monomers have been studied as optical materials having a high refractive index ${ }^{9}$ or as transparent materials for radiation shielding plates. ${ }^{10}$ In the case of optical glasses, the introduction of metal ions having a high polarizability and relatively large ionic radius $\left(\mathrm{Pb}^{2+}, \mathrm{Ba}^{2+}, \mathrm{La}^{3+}\right)$ has been employed in order to increase their refractive

\footnotetext{
* Present address: Hitachi Cable Ltd., 5-1 Hitaka-cho, Hitachi-shi, Ibaraki 319-14, Japan.
} 
indices.

However, polymerizable monomers containing heavy metal ions have proved difficult to dissolve in vinyl monomers such as styrene and methyl methacrylate. For example, the solubility of lead and barium salts of acrylic acid and methacrylic acid are low in these vinyl monomers. Matsuda and Miyoshi ${ }^{8}$ found experimentally that heavy metal salts of ethylene glycolmethacrylate-phthalate and ethylene glycolmethacrylate-maleate are partially soluble or insoluble in styrene and methyl methacrylate. Furthermore, vinyl monomers containing heavy metal ions show a tendency to become heterogeneous due to ionic associations or precipitations when polymerized. Accordingly, very few investigations on transparent polymers containing heavy metal ions and their optical properties have been reported. ${ }^{11}$

In the previous study, we synthesized new types of transparent resins containing $\mathrm{Pb}^{2+}$ and $\mathrm{Ba}^{2+}$ using methacrylic acid (or acrylic acid) and aromatic carboxylic acids. ${ }^{12}$ The effect of the metal ions on the optical properties was also clarified by separately obtaining the molar refraction $\left(\left(R_{\mathrm{u}}\right)\right)$ and the molar volume $\left(V_{\mathrm{u}}\right)$ in the Lorentz-Lorenz equation (eq 1), ${ }^{13,14}$

$$
\left(n_{\mathrm{D}}^{2}-1\right) /\left(n_{\mathrm{D}}^{2}-2\right)=\left(R_{\mathrm{u}}\right) / V_{\mathrm{u}}=\left(R_{\mathrm{u}}\right) \cdot \rho / M_{\mathrm{u}}
$$

where $n_{\mathrm{D}}$ is the refractive index of a resin, $\rho$ is the density, and $M_{\mathrm{u}}$ is the residue molecular weight. The introduction of heavy metal ions leads to an increase of the resin refractive indices due to their large effect on lowering $V_{\mathrm{u}}$. Since these resins have a good transparency and a high refractive index, application as polymer optical waveguides has been investigated. ${ }^{15}$

In spite of extensive studies on optical properties of these resins, their structures have not been investigated in detail and the reason why these resins are transparent at a high concentration of heavy metal ion is still obscure. In this article, the effects of several carboxylic acids on the transparency and optical properties of monomer composites and resins are in- vestigated. Their structures are also discussed on the basis of optical properties and spectroscopic analyses of monomer cmposites.

\section{EXPERIMENTAL}

\section{Preparation of Monomer Composites and Resins Containing $\mathrm{Ba}^{2+}$}

Monomer composites and resins containing $\mathrm{Ba}^{2+}$ were obtained by the method shown in Figure 1. Methacrylic acid (MA) and acrylic acid (AA) were distilled in vacuo. Cinnamic acid (CA) and 3-phenyl propionic acid (3-PPA) were recrystallized in benzene. The molar ratios of MA (or AA)/CA (or 3-PPA) were $80 / 20$ and $65 / 35$. Chlorostyrene was obtained by distillation of the commercial mixture (ortho/para= 60/40, Mitsubishi Gas Co., Ltd.). Barium hydroxide monohydride $\left(\mathrm{Ba}(\mathrm{OH})_{2} \cdot \mathrm{H}_{2} \mathrm{O}\right)$ and barium ethylate $\left(\mathrm{Ba}\left(\mathrm{OC}_{2} \mathrm{H}_{5}\right)_{2}\right)$ were of reagent grade. Di-myristyl peroxydicarbonate (Nippon Yushi Co., Ltd.) was used as a radical initiator without purification. MA or AA, and CA or 3-PPA were reacted with different concentrations of $\mathrm{Ba}(\mathrm{OH})_{2} \cdot \mathrm{H}_{2} \mathrm{O}$ or $\mathrm{Ba}\left(\mathrm{OC}_{2} \mathrm{H}_{5}\right)_{2}$ to obtain complex (I). After mixing complex (I) and chlorostyrene, transparent monomer composites (II) were prepared by evaporation of water (or ethanol) and benzene in vacuo. Transparent resins (III) were obtained by thermal polymerization of the monomer composites (II) with $0.2 \mathrm{wt} \%$ radical initiator.

In this study, particular emphasis is placed on the optical properties of resins prepared

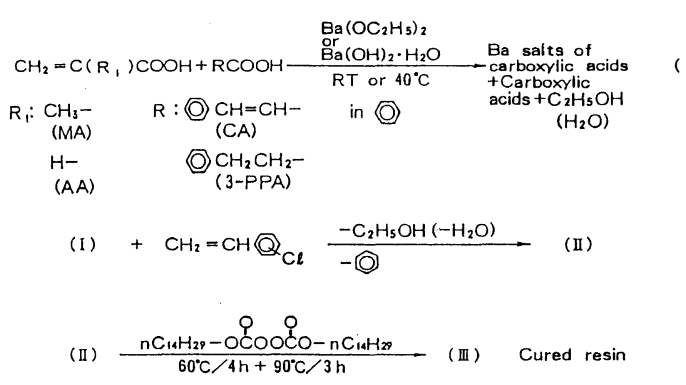

Figure 1. Synthesis of transparent monomer composites and resins containing $\mathrm{Ba}^{2+}$. 
from complex (I) in order to rule out any effects due to chlorostyrene. However, it was impossible to measure them, since no homogeneous resins could be obtained from complex (I). This was due to gelation of complex (I), producing species with a high viscosity and a rapid rate of polymerization when evaporating water (or ethanol) and benzene. Therefore, the optical properties of resins obtained from complex (I) were deduced by extrapolating those of the transparent resins (III) to $0 \mathrm{wt} \%$ of chlorostyrene. Metal content ( $\mathrm{C}$ or $\mathrm{MC}$ ) is defined by eq 2 as the molar fracion of the barium compound which reacted with organic acids in complex (I) or by eq 3 as the molar concentration of barium ion at a constant volume of complex (I),

$$
\begin{gathered}
\mathrm{C}(\mathrm{mol} \%)=\frac{\left[\mathrm{Ba}\left(\mathrm{OC}_{2} \mathrm{H}_{5}\right)_{2} \text { or Ba}(\mathrm{OH})_{2} \cdot \mathrm{H}_{2} \mathrm{O}\right]_{\mathrm{mol}}}{\left[\mathrm{CH}_{2}=\mathrm{C}\left(\mathrm{R}_{1}\right) \mathrm{COOH}\right]_{\mathrm{mol}}+[\mathrm{RCOOH}]_{\mathrm{mol}}+\left[\mathrm{Ba}\left(\mathrm{OC}_{2} \mathrm{H}_{5}\right)_{2} \text { or } \mathrm{Ba}(\mathrm{OH})_{2} \cdot \mathrm{H}_{2} \mathrm{O}\right]_{\mathrm{mol}}} \\
\times 100 \\
\mathrm{MC}\left(\mathrm{mol} \mathrm{l}^{-1}\right)=\frac{\left[\mathrm{Ba}\left(\mathrm{OC}_{2} \mathrm{H}_{5}\right)_{2} \text { or Ba}(\mathrm{OH})_{2} \cdot \mathrm{H}_{2} \mathrm{O}\right]_{\mathrm{mol}} \times 1000}{w / \rho}
\end{gathered}
$$

where $w$ and $\rho$ are the weight and density of complex (I) or resins obtained from it, respectively. The densities of complex (I) or its resins were also estimated by extrapolating those of the monomer composites (II) or the transparent resins (III) to $0 \mathrm{wt} \%$ of chlorostyrene. The molar fraction of barium ion (C) is related to the degree of ionization. The value of $\mathrm{C}$ is about $33 \mathrm{~mol} \%$, if all the carboxylic acids in a system are neutralized with a divalent ion of $\mathrm{Ba}^{2+}$. Infrared spectra measurements confirmed that all the barium compound reacted with the carboxylic acids, and there was no difference in the neutralization reaction between $\mathrm{Ba}(\mathrm{OH})_{2} \cdot \mathrm{H}_{2} \mathrm{O}$ and $\mathrm{Ba}\left(\mathrm{OC}_{2} \mathrm{H}_{5}\right)_{2}$.

On comparing the optical properties of various carboxylic acids, the molar fraction of barium ion (C) colud not be used as the metal content, since the differnece in the molecular weight between MA and AA caused a large difference in the total volume of complex (I) or resins at the same molar fraction of barium ion. For example, the total volume of complex (I) composed of $\mathrm{MA}$ and CA was about $78 \mathrm{~cm}^{3} \mathrm{~mol}^{-1}$ at the barium molar fraction of $18.4 \mathrm{~mol} \%$, while that composed of AA and CA had a value of about $67 \mathrm{~cm}^{3} \mathrm{~mol}^{-1}$ at the same barium molar fraction. The optical properties between various carboxylic acids should be compared by considering the barium content at a constant volume. In this case, the molar concentration of barium ion (MC) was used as the barium content instead of its molar fraction.

\section{Preparation of a Barium Salt of Methacrylic Acid}

Into a three-necked flask in which $0.2 \mathrm{~mol}$ of MA was dissolved in $100 \mathrm{ml}$ of acetone, $0.1 \mathrm{~mol}$ of $\mathrm{Ba}(\mathrm{OH})_{2} \cdot \mathrm{H}_{2} \mathrm{O}$ was added gradually at $30^{\circ} \mathrm{C}$. A barium salt which precipitated in the form of a white powder was filtered off and dried in vacuo at about $40^{\circ} \mathrm{C}$. It was confirmed by infrared spectra measurement that this product was the barium salt of methacrylic acid. The barium salt was dissolved together with MA in chlorostyrene to prepare transparent monomer composites with various barium contents. The metal content (C or $\mathrm{MC}$ ) was calculated as the molar fraction of the barium salt against the total amounts of MA or as the molar concentration of barium ion at a constant volume of monomer composites.

\section{Measurements}

The refractive indices $\left(n_{\mathrm{D}}\right)$ and Abbe numbers $\left(v_{\mathrm{D}}\right)$ of monomer composites and resins were measured using an Abbe refractometer. 
The measurements were made at $25^{\circ} \mathrm{C}$ for monomer composites and at room temperature for resins. The Abbe number means the dependency of the refractive index on the wavelength, as shown in eq 4 ,

$$
v_{\mathrm{D}}=\left(n_{\mathrm{D}}-1\right) /\left(n_{\mathrm{F}}-n_{\mathrm{C}}\right)
$$

where $n_{\mathrm{D}}, n_{\mathrm{F}}$, and $n_{\mathrm{C}}$ are the refractive indices at $589.3,486.1$, and $656.3 \mathrm{~nm}$, respectively.

The densities of the monomer composites were measured at $25^{\circ} \mathrm{C}$ using a pycnometer, and those of the resins were measured at room temperature by the hydrostatic weighing technique.

Infrared spectra of monomer composites and resins were obtained on an Hitachi spectrophotometer, Model 260-50. For measurements of the infrared spectra, monomer composites were placed between rock salt plates, while the resins were finely powdered and embedded into potassium bromide disks. Proton nuclear magnetic resonance spectra of the barium salts were obtained on an Hitachi R-250-SCM Fourier transform spectrometer. Deuterated chloroform was used as the solvent in all cases. The internal reference was tetramethyl silane. Ultraviolet and visible spectra of resins were measured wit an Hitachi spectrophotometer Model 340 using a resin plate of $2 \mathrm{~mm}$ thickness.

\section{RESULTS AND DISCUSSION}

\section{Transparency and Structures of Monomer Composites}

The monomer composite (II), made up of two kinds of caboxylic acids as shown in Figure 1, was transparent until about a $20 \mathrm{~mol} \%$ conent of barium ion was reached. On the other hand, the monomer composite composed of only one carboxylic acid such as MA became opaque above $5 \mathrm{~mol} \%$ of barium, due to a dispersed precipitate. This difference of solubility in chlorostyrene seemed to be associated with the structural difference between the two cases. The structural change of carboxylic acids

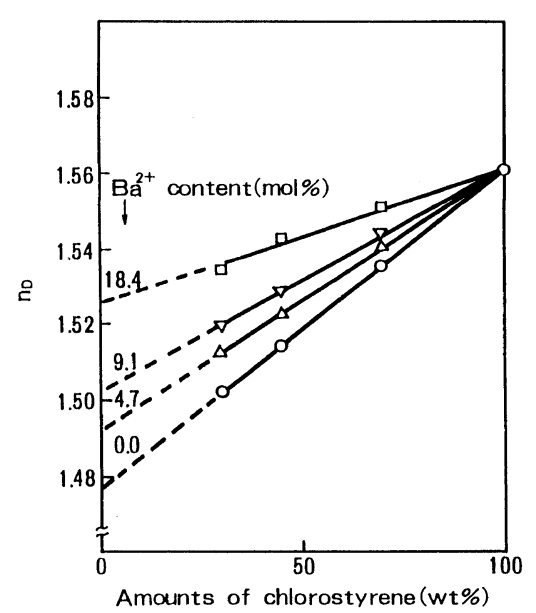

Figure 2. Refractive indices of monomer composites vs. amounts of chlorostyrene. Molar ratio of $\mathrm{MA} / \mathrm{CA}=80 / 20$.

partially neutralized with barium ion resulted in a readily measurable refractive index change. Therefore, refractive indies were measured as a function of the barium content for both cases in order to investigate the existence of structural differences. As described in the experimental section, the barium salts of two kinds of carboxylic acids could not be obtained alone from complex (I), due to gelation during evaporation of water and benzene. The refractive indices of these barium salts were estimated using data on the monomer composites containing chlorostyrene, as shown below.

Figure 2 shows the change of refractive indices of monomer composites containing MA and $\mathrm{CA}$ with the amounts of chlorostyrene at various barium contents. Since the refractive indices $\left(n_{\mathrm{D}}\right)$ are linearly proportional to the amounts of chlorostyrene, they exhibit the additivity of the refractive index of each monomer composite against its weight fraction, as shown in eq 5 ,

$$
n_{\mathrm{D}}=n_{1} \cdot w_{1}+n_{2} \cdot\left(1-w_{1}\right)
$$

where $n_{1}$ and $w_{1}$ are the refractive index and the weight fraction of chlorostyrene, respectively, and $n_{2}$ is the refractive index of the 
barium salt. By extrapolation of each line to 0 $w t \%$ of chlorostyrene, the refractive indix of the barium salt could be experimentally obtained. For heterogeneous monomer composites, the refractive index may be computed by the Lorentz-Lorenz equation assuming additivity of the refractive indices of the constituent phases, as shown in eq $6,{ }^{9}$

$$
\left(n_{\mathrm{D}}^{2}-1\right) /\left(n_{\mathrm{D}}^{2}+2\right)=\sum v_{\mathrm{i}} \cdot\left(n_{\mathrm{i}}^{2}-1\right) /\left(n_{\mathrm{i}}^{2}+2\right)
$$

where $n_{\mathrm{i}}$ and $v_{\mathrm{i}}$ are the refractive indices and volume fractions of the constituent phase of components that make up a monomer composite. However, comparison of the refractive index obtained using eq 5 with that using eq 6 confirmed that these values were in good agreement within an experimental error of 0.001 . The monomer composites containing MA and 3-PPA, AA and CA, and only MA were also treated similarly using eq 5 .

The intercepts of their refractive indices are plotted against the barium molar fraction in Figure 3. Figure 4 shows the results of refractive index changes which are plotted against the molar concentration of barium ion in order to compare the optical properties of various carboxylic acids. The densities of complex (I), which were used for calculation of the molar concentration of barium ion, were obtained by extrapolation of each line to 0 $\mathrm{wt} \%$ of chlorostyrene, since there exists an approximately linear relationship between the reciprocal density, i.e., the specific volume of the monomer composite (II) and the weight fraction of chlorostyrene, as shown in eq 7 ,

$$
1 / \rho=w_{1} / \rho_{1}+\left(1-w_{1}\right) / \rho_{2}
$$

where $\rho, \rho_{1}$ and $\rho_{2}$ are the densities of the monomer composite, chlorostyrene, and the barium salt, respectively, and $w_{1}$ is the weight fraction of chlorostyrene. Each value of $s$ in the figures indicates the solpe of the line calculated by the method of least squares.

As can be seen in Figure 4, every barium salt composed of two kinds of carboxylic acids

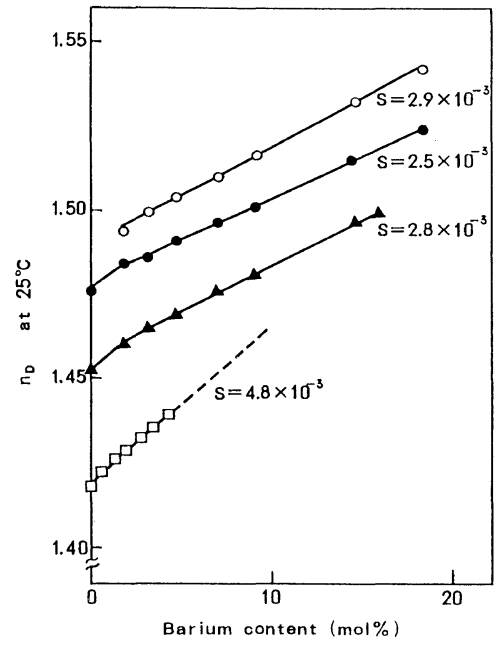

Fugure 3. Refractive index changes with barium content for monomer composites containing $\mathrm{Ba}^{2+}:(\mathrm{O}), \mathrm{AA}$ and $\mathrm{CA}$; $(\mathbf{O})$, MA and CA; $(\boldsymbol{\Delta})$, MA and 3-PPA; $\square)$, MA; molar ratio of $\mathrm{AA}$ or $\mathrm{MA} / \mathrm{CA}$ or $3-\mathrm{PPA}=80 / 20$.

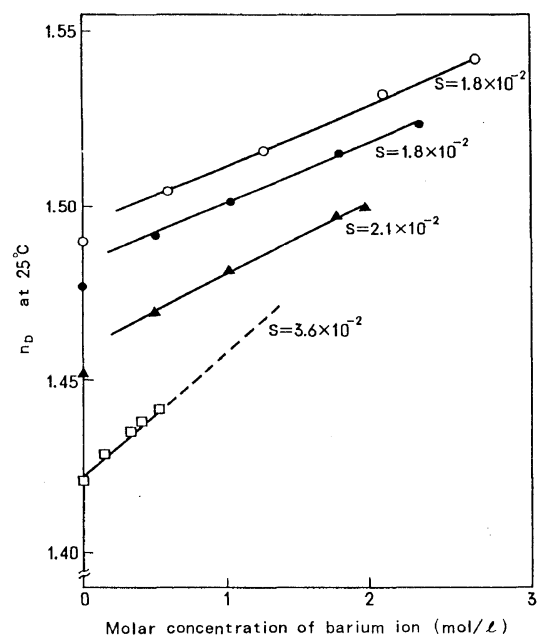

Figure 4. Refractive index changes with molar concentration of the barium ion for carboxylic acids partially neutralized with $\mathrm{Ba}^{2+}:(\bigcirc), \mathrm{AA}$ and $\mathrm{CA} ;(\mathbf{O})$, MA and $\mathrm{CA} ;(\boldsymbol{A}), \mathrm{MA}$ and 3-PPA; $(\square)$, MA; molar ratio of AA or MA/CA or 3-PPA $80 / 20$.

exhibited a smaller refractive index change than that of only MA, although the former has a higher refractive index than the latter. The difference in the refractive index change between the barium salts composed of two kinds 


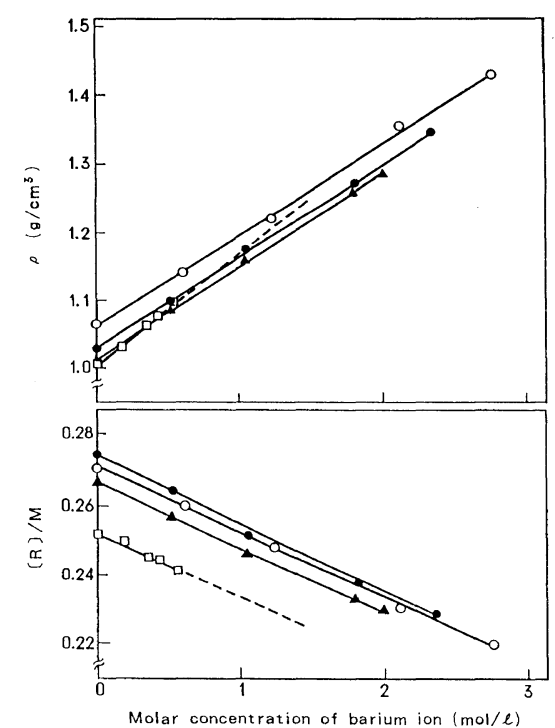

Figure 5. $(R) / M$ and densities $v s$. molar concentration of barium ion for carboxylic acids partially neutralized with $\mathrm{Ba}^{2+}:(\bigcirc)$, AA and $\mathrm{CA} ;(\bigcirc)$, MA and $\mathrm{CA} ;(\boldsymbol{\Delta})$, MA and 3-PPA; ( $\square$ ), MA; molar ratio of $\mathrm{AA}$ or $\mathrm{MA} / \mathrm{CA}$ or $3-\mathrm{PPA}=80 / 20$.

of carboxylic acids was not so pronounced as the result shown in Figure 3.

The values of the molar refraction divided by the molecular weight $((R) / M)$ and densities $(\rho)$ were obtained using the Lorentz-Lorenz equation in order to estimate the relative contribution of these two terms to the refractive index change with the molar concentration of barium ion (Figure 5). $(R) / M$ was calculated by substitution of the density and the refractive index into the Lorentz-Lorenz equation. As shown in Figure 5, the change of $(R) / M$ with molar concentration of barium ion was almost the same for all cases, although its value depended on the carboxylic acid used. The barium salt containing CA showed a larger value of $(R) / M$ due to the higher molar refraction of CA. The increase of $\rho$ was larger for the barium salt of only MA than for all barium salts composed of two kinds of carboxylic acids. In the case of the latter, there was no detectable difference in the density change between $\mathrm{MA}$ and $\mathrm{AA}$, or CA and 3-PPA. This density change behavior was

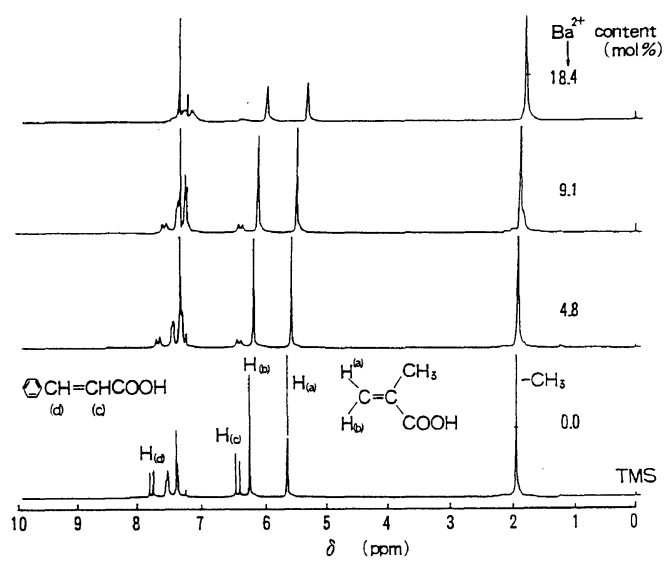

Figure 6. ${ }^{1} \mathrm{H}-\mathrm{NMR}$ spectra of barium salts containing $\mathrm{MA}$ and $\mathrm{CA}$

consistent with the results on differences in the refractive index changes between the various barium salts, as shown in Figure 4. Thus, it was concluded that the density influences the difference in the refractive index change, but not molar refraction.

The increase of $\rho$ with the barium content is clearly attributable to the heavy barium ion which reacted with carboxylic acids. Consequently, structural differences between the barium salt of only MA and those of two kinds of carboxylic acids might lead to differences in both the solubility in chlorostyrene and density change. To clarify this point, further analyses on the structures of various barium salts were undertaken using ${ }^{1} \mathrm{H}$-NMR. Figure 6 shows the ${ }^{1} \mathrm{H}-\mathrm{NMR}$ spectra, at several barium contents, for the barium salts of MA and CA. The relevant peaks of the carboxylic acids were assigned with no barium present. ${ }^{1} \mathrm{H}-\mathrm{NMR}$ measurements were also made for the barium salts of MA and 3-PPA, and for AA and CA, respectively (not shown here). For all cases two characteristic changes of ${ }^{1} \mathrm{H}-\mathrm{NMR}$ spectra with increasing the barium content were observed:

1. All relevant peaks of the carboxylic acids, except the carboxyl group proton, showed a small shift to the upper magnetic field i.e., low chemical shift with an increase of the barium content. 


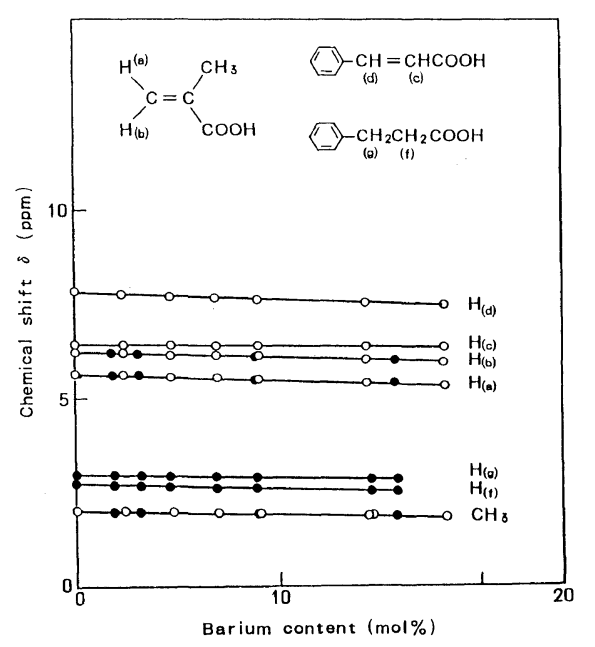

Figure 7. Changes in chemical shifts with barium content for barium salts of two kinds of carboxylic acids: $(O)$, MA and $\mathrm{CA} ;()$, MA and 3-PPA; molar ratio of MA/CA or $3-\mathrm{PPA}=80 / 20$.

2. An increase of the barium content also led to broadening of carboxylic acid line widths.

The chemical shifts of the peaks relevant to MA, CA, and 3-PPA are plotted as a function of barium content in Figure 7. All peaks showed a linear shift with increasing barium content, and the magnitude of the shift was almost the same, regardless of the proton positions. Because barium is a weak paramagnetic species, these isotropic chemical shifts have been attributed to the effects of contact interactions arising from delocalization of unpaired electron density over carboxylate ligands. ${ }^{16}$

Concerning the broadening of peak lines, it is known that an electron transfer ${ }^{17}$ or a hydrogen transfer reaction ${ }^{18}$ between diamagnetic and paramagnetic molecules leads to broadening of proton resonance line widths, and this broadening is proportional to the concentration of the paramagnetic species. As can be seen in Figure 6, it appeared that line broadening is related to barium content. A completely neutralized carboxylate with a barium ion is assumed to have a broad line
Table I. $\mathrm{p} K_{1}$ values of carboxylic acids $\mathrm{a}^{\mathrm{a}}$

\begin{tabular}{cc}
\multicolumn{1}{c}{ Carboxylic acids } & $\mathrm{p} K_{1}$ \\
\hline $\mathrm{CH}_{2}=\mathrm{C}\left(\mathrm{CH}_{3}\right) \mathrm{COOH}$ & 4.66 \\
$\mathrm{CH}_{2}=\mathrm{CHCOOH}$ & 4.26 \\
$\mathrm{CH}=\mathrm{CHCOOH}$ & 4.44 \\
$\mathrm{CH}_{2} \mathrm{CH}_{2} \mathrm{COOH}$ & 4.46 \\
\hline
\end{tabular}

a Measured values at $25^{\circ} \mathrm{C}$ in water.

(From Lange's Handbook of Chemistry. ${ }^{19}$ )

width, since severe broadening of the relevant proton peak of CA was observed at the highest barium content of $18.4 \mathrm{~mol} \%$. However, the relevant peak of a carboxylic acid and that of its barium salt were not observed separately. This means that a rapid exchange reaction took place between them. The exchange reaction may be written as

$$
\begin{aligned}
& \mathrm{RCOO}^{-} \mathrm{Ba}^{2+-} \mathrm{OOC}^{2} \cdot+\mathrm{RCOOH} \rightarrow \\
& \mathrm{RCOOH}+\mathrm{RCOO}^{-} \mathrm{Ba}^{2+-} \mathrm{OOC} \cdot
\end{aligned}
$$

where $\mathrm{RCOOH}$ and $\mathrm{RCOO}^{-}$are carboxylic acid and the carboxylate anion, respectively.

NMR measurements confirmed the formation of ionic bonds between not only $\mathrm{Ba}^{2+}$ and MA (or AA) but also $\mathrm{Ba}^{2+}$ and CA (or 3-PPA). These four carboxylic acids have very similar dissociation canstants $\left(\mathrm{p} K_{1}\right),{ }^{19}$ although measured in water (Table I). However, the barium salt of only CA or 3-PPA was insoluble in chlorostyrene. As described previously, the barium salt of only MA precipitated above a barium content of $5 \mathrm{~mol} \%$. Therefore, it is likely that the following ionic bonds can be formed between two kinds of carboxylic acids and $\mathrm{Ba}^{2+}$, as well as between AA (or MA) and $\mathrm{Ba}^{2+}$.

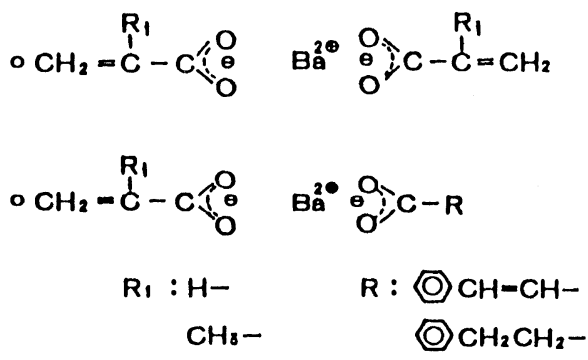


In addition to the formation of these barium carboxylic salts, carboxylic acids are able to co-ordinate and/or associate to the positive barium ion through the carbonyl group, since it has been reported from ionic crystallography that the barium ion has a coordination number of 6 or $12 .^{20,21}$

Molecules with structure (B) would have some advantages regarding improved solubility in chlorostyrene. Their bulky and asymmetric structures, or hydrophobic interactions between an aromatic carboxylic acid and chlorostyrene play roles in weakening the electrostatic interaction with $\mathrm{Ba}^{2+}$, which results in depressing the growth of ionic associations at high barium ion concentrations. This view is supported by the finding that every barium salt composed of two carboxylic acids exhibited a smaller increase of density than that when composed of only MA. On the other hand, the density change of the barium salt composed of two kinds of carboxylic acids was little affected by structural differences between MA and AA, or CA and 3-PPA, as shown in Figure 5. This indicates that there is no significant difference in interactions with $\mathrm{Ba}^{2+}$ between the barium salts composed of two kinds of carboxylic acids.

Polymerization of the transparent monomer composites obtained using two carboxylic acids always gave transparent resins, as shown in Figure 8 . It is likely that the above structure (B) also enables the barium salts to copolymerize in nearly a random state with chlorostyrene, since its bulky structure prevents the association of barium salts. Thus, it is effective to use two kinds of carboxylic acids for obtaining monomer composites and transparent resins at high barium ion concentrations.

\section{Optical Properties of Transparent Resins} Containing $\mathrm{Ba}^{2+}$

Figure 9 shows refractive indices and Abbe numbers of transparent resins prepared by the copolymerizing barium salts of two kinds of carboxylic acids with chlorostyrene. As shown

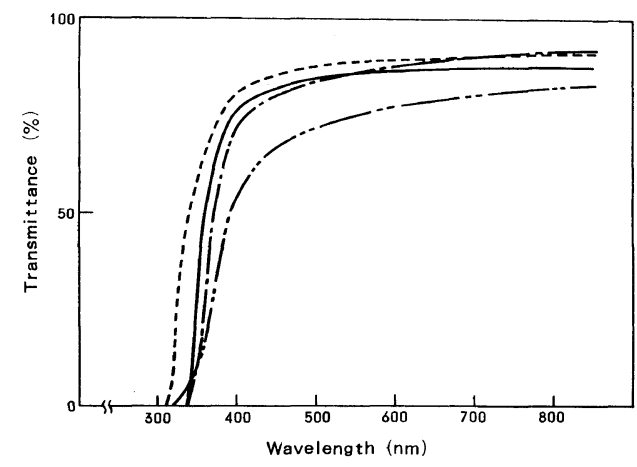

Figure 8. Ultraviolet and visible spectra of resins containing barium salts $(45 \mathrm{wt} \%)$ and chlorostyrene $(55 \mathrm{wt} \%)$; (-) AA and CA; (-- ) AA and 3-PPA; (--) MA and CA; (--.-) MA and 3-PPA; molar ratio of $\mathrm{AA}$ or $\mathrm{MA} / \mathrm{CA}$ or $3-\mathrm{PPA}=80 / 20$. The barium content of all resins is $18.4 \mathrm{~mol} \%$.

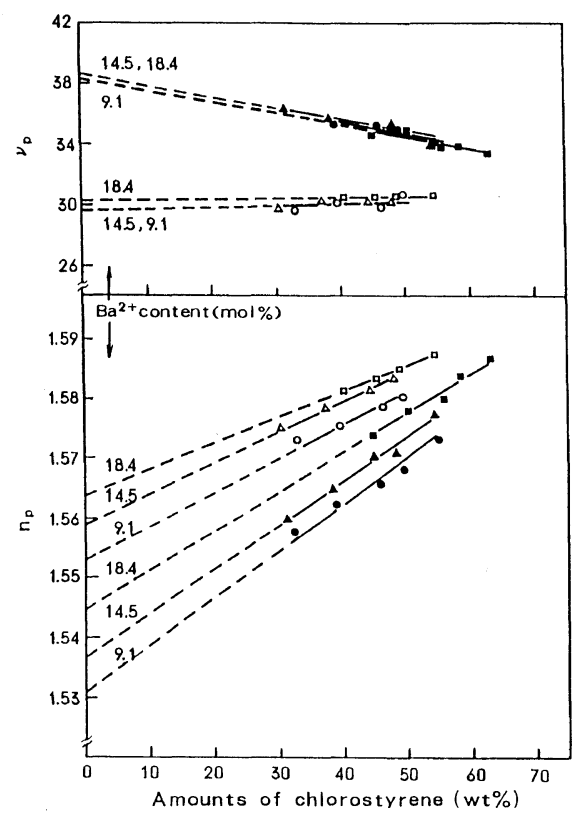

Figure 9. Refractive indices and Abbe numbers $v s$. amounts of chlorostyrene for resins containing $\mathrm{Ba}^{2+}:(\mathrm{O}$, $\triangle, \square), \mathrm{CA} ;(\boldsymbol{O}, \boldsymbol{\Delta}, \mathbf{\square}), 3-\mathrm{PPA} ; \mathrm{MA} / \mathrm{CA}(80 / 20)$; MA/3-PPA (80/20).

in the figure, the refractive indices $\left(n_{\mathrm{p}}\right)$ and Abbe numbers $\left(v_{p}\right)$ of resins exhibit the additivity of the refractive index and Abbe number of each component against its weight fraction. It has been reported that the refractive 
index is linearly dependent on the weight fractional composition for random copolymers such as the methyl methacrylate + styrene copolymers and the acrylonitrile + styrene copolymers. ${ }^{14,22}$ Ohtsuka et al. $^{23}$ also found the same behavior for $n_{\mathrm{D}}$ and $\left(n_{\mathrm{F}}-n_{\mathrm{C}}\right) / n_{\mathrm{D}}$ (the dependence of the refractive index on the wavelength) of the trifluoroethyl methacrylate + diethylene glycol bis(allyl carbonate) copolymers, where $n_{\mathrm{D}}, n_{\mathrm{F}}$, and $n_{\mathrm{C}}$ are refractive indices at wavelengths of 589.3, 486.1 and $656.3 \mathrm{~nm}$, respectively. From Figure 9, the refractive index and Abbe number of the resins composed of carboxylic acids were obtained by extrapolation of each line to $0 \mathrm{wt} \%$ of chlorostyrene, using eq 8 and 9 ,

$$
\begin{aligned}
& n_{\mathrm{p}}=n_{1} \cdot w_{1}+n_{2} \cdot\left(1-w_{1}\right) \\
& v_{\mathrm{p}}=v_{1} \cdot w_{1}+v_{2} \cdot\left(1-w_{1}\right)
\end{aligned}
$$

where $n_{1}, v_{1}$, and $w_{1}$ are the refractive index, Abbe number, and weight fraction of polychlorostyrene, respectively, and $n_{2}$ and $v_{2}$ are the refractive index and Abbe number of the resin composed of barium salts of carboxylic acids, respectively. Resins containing AA and CA (or 3-PPA) were also treated similarly.

The intercepts of their refractive indices and Abbe numbers are plotted against the molar concentration of barium in Figure 10. The refractive index increased linearly with molar concentration of barium content in all cases. The AA resins had higher refractive indices than the MA resins, but there was no detectable difference in the refractive index change between their resins. Nor did increase of the molar ratio of CA have effect on the refractive index change, although the refractive indices of the resins were higher, due to the high molar refraction of CA. On the other hand, the AA resins showed almost the same Abbe numbers as the MA resins in spite of the higher refractive index of the former.

The differences in these optical properties are clarified by molar refraction $\left(\left(R_{\mathrm{u}}\right) / M_{\mathrm{u}}\right)$ and densiy $(\rho)$ in eq 1 (Figure 11). The densities of

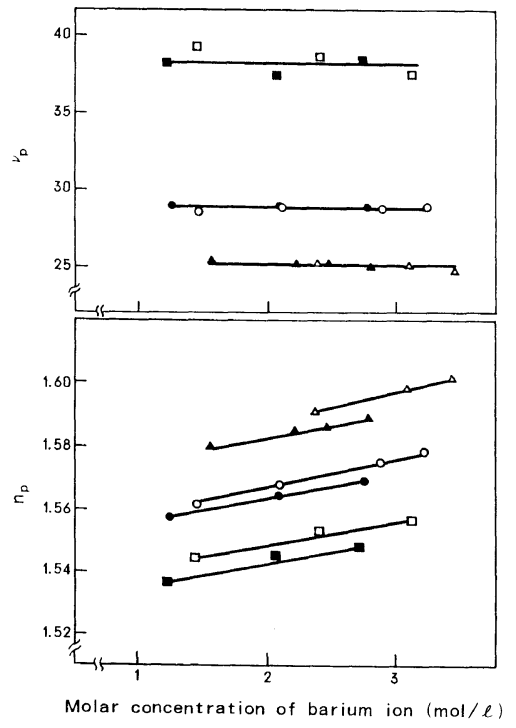

Figure 10. Refractive index and Abbe number changes with molar concentration of barium ion for resins containing $\mathrm{Ba}^{2+}:(\bigcirc), \mathrm{AA} / \mathrm{CA}(80 / 20) ;(\bigcirc), \mathrm{MA} / \mathrm{CA}$ (80/20); ( $\square$ ), AA/3-PPA (80/20); ( $)$, MA/3-PPA (80/20); $(\triangle), \mathrm{AA} / \mathrm{CA}(65 / 35) ;(\boldsymbol{\Delta}), \mathrm{MA} / \mathrm{CA}(65 / 35)$.

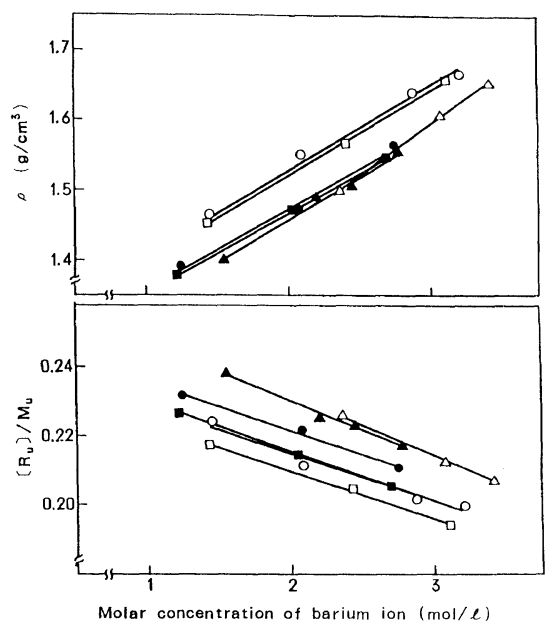

Figure 11. $\left(R_{\mathrm{u}}\right) / M_{\mathrm{u}}$ and densities vs. molar concentration of barium ion for resins containing $\mathrm{Ba}^{2+}:(\mathrm{O}), \mathrm{AA} / \mathrm{CA}$ (80/20); (О), MA/CA (80/20); ( $\square)$, AA/3-PPA (80/20); (ם), MA/3-PPA $(80 / 20) ;(\triangle)$, AA/CA $(65 / 35) ;(\boldsymbol{\Delta})$, MA/CA $(65 / 35)$.

resins composed of barium salts of carboxylic acids were obtained in a similar manner as the monomer composites, using eq 7 , since the 
reciprocal density of the resins increased linearly with the weight fraction of chlorostyrene. The AA resins had larger densities than the MA resins at the same molar concentration of barium ion, but there was almost no difference in the density change between them. Increase of molar ratio of CA caused a larger decrease of density for the AA resins than MA resins, although the former still exhibited a slightly higher density than the latter. CA was found to interfere strongly with the AA resins in their compact states. On the other hand, the slopes decreased for $\left(R_{\mathrm{u}}\right) / M_{\mathrm{u}}$ with the molar concentration of the barium ion and were approximately equal for all cases. The AA resins showed values of $\left(R_{\mathrm{u}}\right) / M_{\mathrm{u}}$ very close to those of the MA resins at $35 \mathrm{~mol} \%$ of $\mathrm{CA}$, unlike the case at $20 \mathrm{~mol} \%$ of CA. This might be due to the large effect of CA on increasing $\left(R_{\mathrm{u}}\right) / M_{\mathrm{u}}$ of the AA resins.

Observations of $\left(R_{\mathrm{u}}\right) / M_{\mathrm{u}}$ and density for the resins were consistent with the rsults for the monomer composites. This means that polymerization results in no significant change in structureal differences among various barium salts. To confirm this point, IR spectra were measured before and after thermal curing, using the monomer composites containing MA, and CA or 3-PPA (Figure 12). In the case containing $\mathrm{CA}$, the absorption peak due to $=\mathrm{C}=\mathrm{C}$ - was observed at $1640 \mathrm{~cm}^{-1}$ even after curing, while in the case of 3-PPA, this peak completely disappeared. This indicates that the peak at $1640 \mathrm{~cm}^{-1}$ is attributable to the unreacted double bond of CA. It is therefore thought that $\mathrm{CA}$ forms the side chain of an AA or MA polymer through the ionic bond with $\mathrm{Ba}^{2+}$, as does 3-PPA. In Figure 13 the volume shrinkage provoked by polymerization was obtained using eq $10,{ }^{24}$

$$
S(\%)=\left(V_{\mathrm{m}}-V_{\mathrm{r}}\right) / V_{\mathrm{m}} \times 100
$$

where $V_{\mathrm{m}}$ and $V_{\mathrm{r}}$ are the specific volumes for a monomer composite and cured resin. The volume shrinkage decreased with barium content, but there was no difference in volume

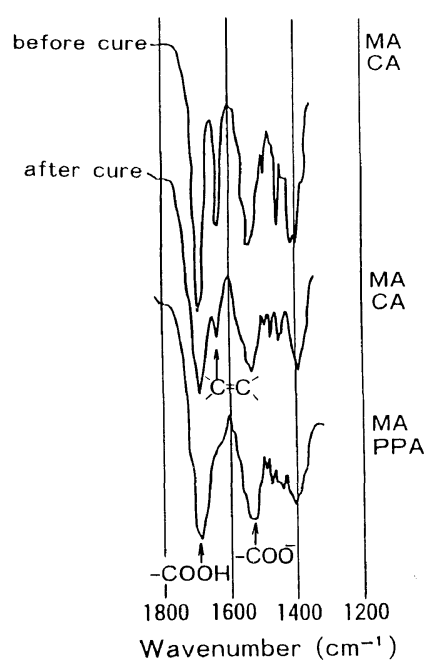

Figure 12. Infrared absorption spectra of a monomer composite and resins containing $\mathrm{Ba}^{2+}(14.5 \mathrm{~mol} \%)$.

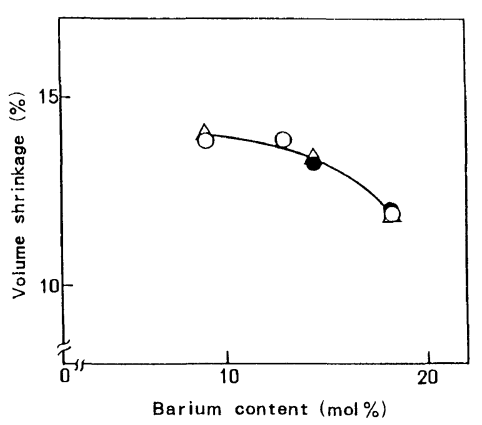

Figure 13. Dependence of volume shrinkage by polymerization on the barium content for monomer composites containing barium salts $(55 \mathrm{wt} \%)$ and chlorostyrene $(45 w t \%):(\bigcirc)$, AA and MA; $(\bigcirc)$, MA and CA; $(\triangle)$, MA and 3-PPA; molar ratio of AA or MA/CA or $3-P P A=80 / 20$.

shrinkage between MA and AA, or CA and 3-PPA. The structural differences among various monomer composites were thus concluded to be little affected by polymerization.

From Figure 11 it can be seen that the polymer chains of the AA resins exist in a compacter state than those of the MA resins and this difference is little affected by the neutralization reaction with $\mathrm{Ba}^{2+}$. A high refractive index could be obtained by increasing $\left(R_{\mathrm{u}}\right) / M_{\mathrm{u}}$ or increasing the density, as shown in 
eq 1 . When increasing $\left(R_{\mathrm{u}}\right) / M_{\mathrm{u}}$, decrease of the Abbe number would be inevitable, since $\left(R_{\mathrm{u}}\right)$ is strongly associated with the polarizabiliy of a molecule. Increase of the density would have no effect on change of Abbe number. Accordingly, that the AA resin had a higher refractive index without a decrease of an Abbe number, at the same barium content, than the $\mathrm{MA}$ resins, can be explained by the effect of AA on the increase of density. The simultaneous use of CA (or 3-PPA) and MA (or AA) was effective to maintain the transparency of resins at high barium ion concentrations, and increase the refractive index due to large $\left(R_{\mathrm{u}}\right)$ of the former. However, this caused a decrease of density, and the magnitude of which was larger for AA resins having higher density than MA resins. This means a small effect from CA or 3-PPA on increase of the refractive index. Also, the use of $\mathrm{CA}$ or 3-PPA resulted in decrease in Abbe number due to their large polarizability.

\section{CONCLUSIONS}

Monomer composites containing an aromatic carboxylic acid and methacrylic acid (or acrylic acid) partially neutralized with a barium compound were soluble in chlorostyrene at high barium ion concentrations, compared to those containing only one carboxylic acid. Improved solubility was associated with the structures of the monomer composites. The presence of an ionic crosslink composed of an aromatic carboxylate ion and methacrylate ion (acrylate ion) bridged with barium ion was effective for depressing the growth of ionic associations at high barium ion concentration, due to its bulky and asymmetric structure. Copolymerization of the transparent monomer composites always gave transparent resins. The results of IR measurements and volume shrinkage by polymerization led to the conclusion that aromatic carboxylic acid fromed the side chain of a polymer through an ionic crosslink composed of an aromaic carboxylate ion and metacrylate ion (or acrylate ion) bridged to barium ion. It seems that this bulky structure would also be useful for maintaining the transparency of the resins.

The refractive indices and Abbe numbers of resins were measured and the effects of carboxylic acids on them were interpreted by $\left(\left(R_{\mathrm{u}}\right) / M_{\mathrm{u}}\right)$ and density in the Lorentz-Lorenz equation, where $\left(R_{\mathrm{u}}\right)$ and $M_{\mathrm{u}}$ are the unit molar refraction and residue molecular weight, respectively. The effect of acrylic acid on increased density of resins was pronounced, so that resins with acrylic acid had higher refractive indices, without decrease in Abbe numbers, than resins with methacrylic acid. The simultaneous use of cinnamic acid (or 3-phenyl propionic acid) and methacrylic acid (or acrylic acid) was effective for maintaining the transparency of the resins at high barium ion concentrations, but this caused decrease in the resin density. This means a small effect from aromatic carboxylic acids on the increased refractive index of the resins.

Acknowledgments. We express our sincere appreciation to Dr. S. Numata of Hitachi Research Laboratory, Hitachi Ltd., for his helpful dicussions.

\section{REFERENCES}

1. A. Eisenberg and M. King, "Ion-Containing Polymers," Academic Press, New York, N. Y., 1977.

2. E. P. Otocka, J. Polym. Sci., Revs. Macromol. Chem., C, 5, 275 (1971).

3. A. Eisenberg, J. Polym. Sci., Symposium, No. 45, 99 (1974).

4. W. J. Macknight and T. R. Earnest, J. Polym. Sci., Makromol. Rev., 16, 41 (1981).

5. R. A. Weiss and P. K. Agarwal, J. Appl. Polym. Sci., 26, 449 (1981).

6. F. Ide and A. Hasegawa, Kobunshi, 18, 616 (1969); F. Ide and A. Hasagawa, Kobunshi, 18, 712 (1969).

7. E. Banks, Y. Okamoto, and Y. Ueda, J. Appl. Polym. Sci., 25, 359 (1980).

8. H. Matsuda and N. Miyoshi, J. Appl. Polym. Sci., 17, 1941 (1973); H. Matsuda, J. Appl. Polym. Sci., 17, 2877 (1973).

9. Y. Ohtsuka, Kobunshi, 27, 90 (1978). 
10. H. Nagai, H. Uehara, and K. Nunokawa, U. S. Patent 4129524 (Dec. 12, 1978).

11. M. Miya and S. Mima, The Quarterly Report of the Government Industrial Research Institute, Osaka, 27, 129 (1979); M. Miya and S. Mima, The Quarterly Report of the Government Industrial Research Institute, Osaka, 27, 136 (1979).

12. S. Eguchi, T. Koyama, H. Asano, and M. Wajima, Kogaku, 15, 50 (1986).

13. A. F. Forziation in "Optical Methods," Vol. 7, Part 2, Analytical Chemistry of Polymers," G. M. Kline, Ed., Interscience Publishers, New York, N. Y., 1962, p 136.

14. R. B. Beeves, J. Polym. Sci., Polym. Phys. Ed., 12, 1407 (1974).

15. S. Eguchi, H. Asano, A. Kannke, and M. Ibamoto, Jpn. J. Appl. Phys., 28, L2232 (1989).

16. E. de Boer and $H$. van Willingen in "Nuclear Magnetic Resonance of Paramagnetic Systems," Vol.
2, "Progress in N.M.R. Spectroscopy," J. W. Emsley, J. Feeney, and L. H. Sutchiffe, Ed., Pergamon Press Ltd., Oxford, U. K., 1967, pp 111-161.

17. E. de Boer and C. Maclean, J. Chem. Phys., 44, 1334 (1966).

18. R. W. Kleilick and S. I. Weissman, J. Am. Chem. Soc., 88, 2645 (1966).

19. J. A. Dean, Ed., "Lange's Handbook of Chemistry," 13 th Ed., McGraw-Hill Inc., Tokyo, 1972.

20. R. D. Shannon and C. T. Prewitt, Acta Crystallogr., B25, 925 (1969).

21. R. D. Shannon, Acta Crystallogr., A32, 751 (1976).

22. S. Ayano and T. Murakawa, Kobunshi Kogaku, 29, 723 (1972).

23. Y. Ohtsuka, T. Senga, and H. Yasuda, Appl. Phys. Lett., 25, 659 (1974).

24. J. Kulawik, Z. Szeglowski, T. Czapla, and J. P. Kulawik, Colloid Polym. Sci., 267, 970 (1989). 